\title{
A research agenda to improve patients' experience of knee replacement surgery: a patient-oriented modified Delphi study of patients of South Asian origin in British Columbia
}

\author{
Stirling Bryan PhD, Laurie J. Goldsmith PhD, Nitya Suryaprakash PhD, Richard Sawatzky PhD RN, \\ Marilyn Mulldoon, Moira Le Mercier, David Moorthy MEd, Rajiv Gandhi MD, \\ Satwinder Kaur Bains PhD, Linda C. Li PhD PT, Mary Doyle-Waters MA MLIS, Sean Brown MD
}

\section{Abstract}

Background: Up to 1 in 5 patients who undergo total knee arthroplasty (TKA) express dissatisfaction with their surgery. Our goal was to understand the experiences of patients of South Asian origin who undergo TKA and to identify a research agenda for this patient population.

\begin{abstract}
Methods: We undertook a modified Delphi study in British Columbia to generate and prioritize potential research topics. An initial list of topics was generated using 3 focus groups with patients of South Asian origin who underwent TKA and their caregivers. Focus group sessions were audiotaped and transcribed, and the data were analyzed using thematic analysis. The resulting Delphi questionnaire was administered over 2 rounds to patients, caregivers and health professionals. The second-round questionnaire included only topics that were strongly supported in the first round. A patient-oriented approach was adopted, with 3 patient partners as full research team members, who contributed to scoping, design, data collection, analysis and interpretation.
\end{abstract}

Results: Twenty-one patients who had undergone TKA and 6 caregivers attended the focus groups. Our analyses resulted in 6 broad themes and 25 research topics, all of which were presented in the first round of the Delphi survey. The survey was completed by 27 patients and 5 caregivers (54\% combined response rate) and by 25 clinicians ( $76 \%$ response rate). Top priorities both for patients and caregivers and for clinicians were promoting exercise following surgery and self-management after hospital discharge. One of the highest ranked topics for patients and caregivers was improving knee implants; this was supported by only $60 \%$ of clinicians.

Interpretation: The patients and caregivers in our study prioritized research on promotion of exercise and self-management following surgery and improvement in knee implants. Future patient-oriented research efforts in Canada should emphasize these topics for this patient population.

Plain language summary: As many as $20 \%$ of patients who have undergone total knee arthroplasty (TKA) are not satisfied with the outcome of their surgery. We need a better understanding of patient experiences and satisfaction with TKA, including differences between ethnic groups. Our team focused on understanding the experiences and satisfaction of patients of South Asian origin who had undergone TKA, as South Asians represent the largest visible minority group in Canada. Our team included universitybased researchers, patients who had undergone TKA, health professionals and policy-makers. Several team members were of South Asian origin, or provided care for patients of South Asian origin, or both. We used group discussions with patients and caregivers of South Asian origin to identify areas for future research. These potential research topics were then ranked by patients and caregivers and by health professionals. This ranking was done using 2 surveys. The second survey included only those topics that had received the most support in the first survey and provided information about other respondents' answers in the first survey. Top priorities for both the patient and caregiver group and the health professionals group were promoting exercise following surgery and self-management after hospital discharge. The third highest ranked topic for patients and caregivers was improving knee implants. This topic was not as strongly supported by health professionals. Having patients as research team members strengthened our study in multiple ways. Our study's findings strongly indicate that the research priorities for patients of South Asian origin who undergo TKA are promotion of exercise and self-management following surgery and improvement in knee implants.

Competing interests: Rajiv Gandhi reports receiving consulting fees from DePuy Synthes outside the submitted work. No other competing interests were declared.

This article has been peer reviewed.

Correspondence to: Stirling Bryan, stirling.bryan@ubc.ca

CMAJ Open 2020. DOI:10.9778/cmajo.20190128 


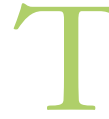

otal knee arthroplasty (TKA) is one of the highest volume surgeries in Canada. ${ }^{1}$ Although most patients who undergo TKA report high levels of satisfaction, a troubling statistic is that up to 1 in 5 patients express dissatisfaction. ${ }^{2,3}$ Drivers of such dissatisfaction include knee-related factors (e.g., ongoing pain), failure to meet presurgery expectations, complications and pain catastrophizing. ${ }^{2,4-14}$

In our previous mixed-methods research, we highlighted key challenges for patients such as postsurgery support needs not being met $^{15}$ and ongoing health limitations. ${ }^{16}$ Although our earlier work offered new insights into patient experiences after TKA, a major limitation was the limited ethnic diversity in the patient sample. This prevented us from exploring variation in satisfaction by ethnicity, a topic that has not been widely investigated. Delivering truly personcentred care requires understanding how care experience varies by ethnic background.

The Canadian South Asian community (including people from India, Pakistan, Sri Lanka and Bangladesh) is the largest visible minority group in Canada. ${ }^{17}$ The need for TKA surgery among patients of South Asian origin appears to differ from that of other groups in Canada, but their experience is equally mixed. For example, Gandhi and colleagues found that, compared with white patients, South Asians presented at a younger age and had greater presurgery functional disability and pain. ${ }^{18,19}$ The same team, however, also found that ethnicity was not predictive of a poorer functional outcome.

Our project's goal was to understand the experiences of patients of South Asian origin who undergo TKA, with a view to identifying a South Asian patient-oriented research agenda for TKA in Canada. Establishing a research agenda focused on a visible minority group allows for targeted research efforts to support evidence development to guide clinical practice improvement, especially in settings serving such minority communities. We were guided by the principles underlying Canada's Strategy for Patient-Oriented Research (SPOR), with its emphasis on collaborative engagement of patients, researchers and clinicians to identify important research topics.

\section{Methods}

\section{Study design}

Using a patient-oriented approach, we conducted a modified Delphi study that included focus group sessions followed by 2 rounds of surveys. After discussions among key team members including patient partners, the project commenced with a half-day workshop. This provided the opportunity for sharing insights into South Asian culture, which was a key learning opportunity for the team. Further, the session enabled team members to share information about health, to review the team's earlier research findings and to discuss the project.

We employed a modified Delphi process to develop a ranked list of potential research topics aimed at improving the experience of TKA for patients of South Asian origin. The Delphi technique is widely used in health research, often to establish consensus among experts through multiple survey rounds. ${ }^{20}$ In contrast to a traditional Delphi process, our process involved using focus groups to generate the initial list of potential research topics, ${ }^{20,21}$ we employed 2 survey rounds, to avoid participant fatigue, ${ }^{22}$ and we included 2 groups of survey recipients (patients and caregivers, and clinicians). Patient partners supported the key step of moving from the focus group themes to the Delphi survey topics by reviewing themes, editing the language and piloting the survey. We used the focus groups as a means by which to listen effectively to the voices of those with lived experience, as our intention was to have these voices guide the selection of survey topics.

\section{Study setting}

The study took place in British Columbia, Canada. The provincial insurance program in $\mathrm{BC}$ pays for medically necessary services provided by physicians and midwives, dental and oral surgery performed in a hospital, eye examinations if medically required, and some orthodontic, diagnostic and laboratory services. The focus groups were held in 2017 on July 30, Aug. 12 and Aug. 19, and the Delphi survey rounds were administered in March and April 2018.

\section{Study participants}

Study participants included patients of South Asian origin who had undergone TKA or their caregivers, as well as health professionals who provided care to patients of South Asian origin. Eligible patients had to have had TKA surgery for osteoarthritis in Canada in the previous 2 years (to ensure we heard from patients and caregivers with recent surgical experience), be over 19 years of age, have South Asian ancestral roots and be able to converse in English or Punjabi or both languages. If an eligible patient was unwilling to participate, we invited the patient's caregiver. This reflects our appreciation, driven by our earlier qualitative work, ${ }^{15}$ of the impact of the surgery and its outcomes on both the patient and their caregiver(s).

Health care professionals included physiotherapists, orthopedic surgeons, primary care physicians, orthopedic nurses and occupational therapists who self-identified as providing care for patients of South Asian origin who undergo TKA.

Patients and caregivers participated in the focus groups and the Delphi survey; health professionals participated in the Delphi survey only. We conducted 3 focus groups, with 6-10 patients and caregivers in each group. ${ }^{21}$ The target sample size for the Delphi survey was 25-40 patients and caregivers and 15-20 clinicians, reflecting feasibility constraints and the sample sizes of similar health research surveys. ${ }^{20}$

Patients and their caregivers were recruited through community outreach, health system contacts, word of mouth and a radio announcement made about the study on a popular South Asian radio station. Where possible we sought diversity in terms of sex and age. Health professionals were recruited through research team contacts.

With the support of our research team's patient partners, we identified potential participation barriers and, where possible, overcame them. For example, approaches were made outside of work hours, transportation challenges were considered, participant language and literacy issues were 
accommodated, and caregiver and family responsibilities were recognized. In addition, focus groups were held in multiple locations to facilitate participation.

\section{Data collection}

\section{Focus groups}

Two focus groups were conducted in Punjabi and 1 in both "Hinglish" (Hindi-English) and Punjabi. Experienced multilingual facilitators moderated each group. The study research coordinator (N.S.) and a research assistant, both with a South Asian background, acted as facilitators for all 3 focus groups. Participants were asked to reflect on their entire TKA experience, from diagnosis to longer term outcomes, using a focus group guide (Appendix 1, available at www.cmajopen.ca/ content/8/1/E226/suppl/DC1).

To develop this guide, we drew on our previous TKArelated qualitative research, ${ }^{15}$ discussion among members of the research team, including patient and health professional partners, and guidance from our qualitative research leads (L.J.G., N.S.). Discussion topics were open ended; the focus group guide was followed to ensure consistency. At the end of each focus group, the facilitator and note taker wrote up detailed notes. Each focus group lasted approximately 2 hours, and all participants received a small honorarium and had their costs reimbursed.

All focus groups were audiotaped and transcribed by professional transcribers. The Punjabi discussions were transcribed in Punjabi and then translated. The research coordinator and research assistant read the final transcripts to ensure quality and accuracy. All names were removed from transcripts.

\section{Modified Delphi survey}

In the first round, participants were asked to rate all potential research topics presented using a 5-point scale (ranging from essential to unimportant). In the second round, participants were again asked to indicate the importance of the topic using the same scale. Topics in this round consisted of those that had received strong support either from patients and caregivers or from clinicians in the first round. Strong support was defined as at least $70 \%$ of patients and caregivers or clinicians identifying the topic as essential or very important. This threshold is commonly applied in Delphi studies.

For each topic in the second round, participants were also given the distribution of responses in the first round, for patients and caregivers combined, and for clinicians, and a reminder of their own response in the first round (Figure 1). In the second round, participants could either change the response they had given in the previous round or retain their earlier response.

The Delphi survey was piloted by patient partners and other team members. In the survey, participants had the option of completing an online survey in English or a postal survey in English or Punjabi. The second round of the Delphi survey was conducted 3 weeks after the first round. Participants received a small honorarium at the end of the second round. As a reminder, all participants were called in advance of receiving the survey and again a few days after receipt.

\begin{tabular}{|c|c|c|c|c|c|c|}
\hline \multirow[b]{2}{*}{ प्रा़্সरी /Essential } & $\begin{array}{l}\text { Your } \\
\text { current } \\
\text { response }\end{array}$ & \multicolumn{5}{|c|}{$\begin{array}{l}\text { First round responses } \\
\text { No. of people who answered the first round } n=63\end{array}$} \\
\hline & 0 & \multirow[b]{2}{*}{23} & \multirow[b]{2}{*}{24} & \multirow{3}{*}{12} & \multirow{3}{*}{4} & \multirow{3}{*}{0} \\
\hline घगुउ क़ढ़ी /Very important & 0 & & & & & \\
\hline स़त्रठी /Important & O & & & & & \\
\hline 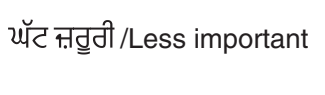 & O & \multirow[t]{2}{*}{ Essential } & $\begin{array}{c}\text { Very } \\
\text { important }\end{array}$ & \multirow{2}{*}{$\begin{array}{c}\text { Important } \\
\text { ur respons }\end{array}$} & \multirow[t]{2}{*}{$\begin{array}{l}\text { Less } \\
\text { important }\end{array}$} & \multirow[t]{2}{*}{ Unimportant } \\
\hline / गौठ स़तूठी /Unimportant & 0 & & & & & \\
\hline
\end{tabular}

Figure 1: Sample Delphi question from the second-round survey. The research topic for this question was information on lifestyle changes (e.g., weight loss, diet, exercise) to prevent or delay osteoarthritis. 
Table 1: Patient research priorities elicited from the focus group discussion

Research theme

Avoiding knee replacement surgery

\begin{tabular}{|l}
\hline \\
\hline $\begin{array}{l}\text { Preparing for and deciding when to } \\
\text { have knee replacement surgery }\end{array}$
\end{tabular}

have knee replacement surgery

\begin{tabular}{|l}
\hline \\
\hline \\
\hline \\
\hline Knee implants \\
\hline Surgical cuts \\
\hline
\end{tabular}

Surgical cuts

Recovery in hospital

(Imp

(2)

Recovery longer term (i.e., after hospital discharge)
Research topics

Information on lifestyle changes (e.g., weight loss, diet, exercise) to prevent or delay osteoarthritis

Improving other surgical techniques (e.g., arthroscopy) to avoid or delay need for knee replacement surgery

Managing knee symptoms (e.g., use of pain medication) to avoid or delay need for knee replacement surgery

Understanding differences between patient and surgeon views on the right time for knee replacement surgery

Improving wait times for surgery

Effectively managing knee pain before surgery (e.g., medication, complementary and alternative medicine such as massage, homeopathy, diet)

Information on lifestyle changes (e.g., weight loss, diet, exercise) before surgery to improve recovery after surgery

Improving patient understanding of what to expect during and after surgery

Providing emotional and psychological support to patients before surgery from other patients

Providing emotional and psychological support to patients before surgery from professional counsellors

Improving knee implants that allow for kneeling, squatting and walking downhill

Improving surgical practices (e.g., stitching) for best healing and scar minimization

Understanding the role of genetics in surgical scar formations

Managing other illnesses while in hospital including medication interaction

Promoting respectful behaviour between patients and clinicians in clinical settings Improving practices for physiotherapy after surgery

Understanding differences between the patient and clinician views on the right time to discharge from the hospital

Effectiveness of discharge to a rehabilitation hospital before being sent home

Integrating family doctors into recovery after surgery at the hospital and after discharge from hospital

Exploring the best role of the surgeon after hospital discharge

Effective use of pain medication after hospital discharge

Effective support from the health care system after surgery

Effective self-management after hospital discharge

Promoting exercise following surgery

Providing effective support to patients with ongoing recovery problems

\section{Data analysis}

\section{Focus groups}

Data were analyzed using a thematic analysis approach. ${ }^{23,24}$ Using version 10 of the NVivo qualitative data analysis software (QSR International), 2 members of the research team (L.J.G., N.S.) created the initial coding framework using line-by-line coding and a combination of independent and consensus work. The resulting themes and associated quotes were discussed at a meeting of the full research team (including our team's patient partners [M.M., M.L., D.M.]), and then consensus work was done to distill the research topics for use in the first round of the Delphi surveys. This multifaceted approach helped ensure analytic rigour. ${ }^{25,26}$ Our patient partners and others on the research team further reviewed the final list of topics to ensure appropriateness of language and framing.

\section{Modified Delphi survey}

For each survey question, the distribution of responses was plotted for each stakeholder group separately. For each topic, the proportion of respondents indicating strong support (i.e., rating the topic as either "essential" or "very important") was calculated separately by stakeholder group.

\section{Patient engagement}

We included 3 patient partners (M.M., M.L., D.M.) as full members of our research team, who contributed to study scoping and design, data collection, data analysis and interpretation, and knowledge translation. 


\begin{tabular}{|c|c|c|}
\hline \multirow[b]{2}{*}{ Characteristic } & \multicolumn{2}{|c|}{ No. (\%) of respondents } \\
\hline & $\begin{array}{l}\text { Patients } \\
n=31\end{array}$ & $\begin{array}{c}\text { Caregivers } \\
\quad n=5\end{array}$ \\
\hline \multicolumn{3}{|l|}{ Age, yr } \\
\hline$\leq 50$ & $1(3)$ & $1(20)$ \\
\hline $51-60$ & $1(3)$ & \\
\hline $61-70$ & $14(45)$ & $3(60)$ \\
\hline $71-80$ & $12(39)$ & $1(20)$ \\
\hline$>81$ & $3(10)$ & \\
\hline \multicolumn{3}{|l|}{ Sex } \\
\hline Female & $19(61)$ & $3(60)$ \\
\hline Male & $12(39)$ & $2(40)$ \\
\hline \multicolumn{3}{|l|}{ Currently working } \\
\hline Yes & $10(32)$ & $3(60)$ \\
\hline No & $21(68)$ & $2(40)$ \\
\hline \multicolumn{3}{|l|}{ Education } \\
\hline Did not complete high school & $10(32)$ & \\
\hline High school diploma & $9(29)$ & $1(20)$ \\
\hline $\begin{array}{l}\text { College or technical school } \\
\text { diploma or degree }\end{array}$ & $3(10)$ & $3(60)$ \\
\hline \multicolumn{3}{|l|}{$\begin{array}{l}\text { Undergraduate university } \\
\text { degree }\end{array}$} \\
\hline Graduate university degree & $6(19)$ & $1(20)$ \\
\hline Other (no formal education) & $3(10)$ & \\
\hline
\end{tabular}

\section{Ethics approval}

Before we recruited subjects and collected data, we received harmonized institutional review board approval from the University of British Columbia Clinical Research Ethics Board (H17-01067). All participants provided informed consent.

\section{Results}

\section{Focus groups}

Fifty-one patients who underwent TKA and caregivers were identified, of whom 47 (92\%) were deemed eligible to participate. Thirty-nine $(83 \%)$ of those eligible consented to participate and 27 (57\%) attended a focus group (21 patients, 6 caregivers). Ineligible patients included 1 with a partial knee replacement, 2 who had surgery outside the 2-year window and 1 who had surgery outside Canada. Of the 27 focus group attendees, $19(70 \%)$ were women; their age varied from 50 to 93 years and all were from India and had lived in Canada for over 10 years. The thematic analysis revealed 6 broad themes and 25 research topics (Table 1 ).

\section{Table 3: Characteristics of clinicians who participated in the} surveys

\begin{tabular}{|c|c|}
\hline Characteristic & $\begin{array}{c}\text { No. (\%) of respondents } \\
n=27\end{array}$ \\
\hline \multicolumn{2}{|l|}{ Sex } \\
\hline Female & $13(48)$ \\
\hline Male & $14(52)$ \\
\hline \multicolumn{2}{|l|}{ Type of practice } \\
\hline Orthopedic surgery & $7(26)$ \\
\hline Physiotherapy & $8(30)$ \\
\hline Occupational therapy & $3(11)$ \\
\hline Family medicine/general practice & $8(30)$ \\
\hline Orthopedic nursing & $1(4)$ \\
\hline \multicolumn{2}{|l|}{ South Asian ethnicity } \\
\hline No & $15(56)$ \\
\hline Yes & $12(44)$ \\
\hline \multicolumn{2}{|l|}{$\begin{array}{l}\text { Length of time providing care to South } \\
\text { Asian patients who undergo TKA, yr }\end{array}$} \\
\hline$<5$ & $7(26)$ \\
\hline $6-10$ & $3(11)$ \\
\hline$>10$ & $17(63)$ \\
\hline $\begin{array}{l}\text { Note: This table describes the clinician who } \\
\text { survey. Of this group, } 25 \text { responded to the }\end{array}$ & $\begin{array}{l}\text { ed to the first round of the } \\
\text { und survey. }\end{array}$ \\
\hline
\end{tabular}

\section{Modified Delphi survey}

Fifty-nine patients and caregivers and 33 clinicians agreed to participate, with $36(61 \%)$ and $27(82 \%)$ completing the firstround survey, respectively (Table 2, Table 3). The secondround survey was administered only to those who responded to the first round; 27 patients and 5 caregivers (89\%) and 25 $(93 \%)$ clinicians completed it. Across both rounds, all responding clinicians used the online survey, while 21 patients and caregivers chose the postal survey.

Fifteen topics met the "strong support" criterion and moved through to the second-round survey (Table 4). When we compared responses between rounds, we found that 38 respondents (67\%) kept the same response across all questions, and where we did see a change it was typically an upward shift (e.g., from a rating of important to very important).

Table 4 shows the proportion of respondents indicating that the topic was either essential or very important (representing strong support). For nearly all topics, the proportion of respondents indicating strong support increased from the first to the second round. Among patients and caregivers, 26 respondents declared strong support for all 15 topics. There was much greater discrimination by clinicians, with only 7 topics receiving strong support from over $80 \%$ of respondents.

The highest levels of endorsement by patients and caregivers, with 30 respondents strongly supporting the topic, were for promoting exercise following surgery, improving practices for physiotherapy after surgery, and improving patient understanding of surgery and aftercare. 
Table 4: Delphi responses for "strong support" (“essential” or "very important”), by survey round and stakeholder group

\begin{tabular}{|c|c|c|c|c|c|c|}
\hline \multirow[b]{3}{*}{ Research topic } & \multicolumn{6}{|c|}{ No. (\%) of respondents; survey round, stakeholder group } \\
\hline & \multicolumn{3}{|c|}{ First round } & \multicolumn{3}{|c|}{ Second round } \\
\hline & $\begin{array}{c}\text { Patients and } \\
\text { caregivers } \\
n=36\end{array}$ & $\begin{array}{c}\text { Clinicians } \\
n=27\end{array}$ & $\begin{array}{l}\text { Combined } \\
n=63\end{array}$ & $\begin{array}{c}\text { Patients and } \\
\text { caregivers } \\
n=32\end{array}$ & $\begin{array}{c}\text { Clinicians } \\
n=25\end{array}$ & $\begin{array}{l}\text { Combined } \\
n=57\end{array}$ \\
\hline $\begin{array}{l}\text { Information on lifestyle changes to prevent or delay } \\
\text { osteoarthritis }\end{array}$ & $25(70)$ & $22(81)$ & $47(75)$ & $27(84)$ & $23(92)$ & $50(88)$ \\
\hline $\begin{array}{l}\text { Improving other surgical techniques to avoid or delay need } \\
\text { for knee replacement surgery }\end{array}$ & $28(78)$ & $7(26)$ & $35(56)$ & $26(81)$ & $7(28)$ & $33(58)$ \\
\hline $\begin{array}{l}\text { Managing knee symptoms to avoid or delay need for knee } \\
\text { replacement surgery }\end{array}$ & $24(67)$ & $18(67)$ & $42(67)$ & & & \\
\hline $\begin{array}{l}\text { Understanding differences between patient and surgeon } \\
\text { views on the right time for knee replacement }\end{array}$ & $30(83)$ & $18(67)$ & $48(76)$ & $29(91)$ & $17(68)$ & $46(81)$ \\
\hline Improving wait times for surgery & $27(75)$ & $19(70)$ & $46(73)$ & $29(91)$ & $18(72)$ & $47(82)$ \\
\hline Effectively managing knee pain before surgery & $26(72)$ & $18(67)$ & $44(70)$ & 27 (84) & $21(84)$ & $48(84)$ \\
\hline $\begin{array}{l}\text { Information on lifestyle changes before surgery to improve } \\
\text { recovery after surgery }\end{array}$ & $25(69)$ & $23(85)$ & $48(76)$ & $28(88)$ & $24(96)$ & $52(91)$ \\
\hline $\begin{array}{l}\text { Improving patient understanding of what to expect during } \\
\text { and after surgery }\end{array}$ & $31(86)$ & $22(81)$ & $53(84)$ & $30(94)$ & $21(84)$ & $51(90)$ \\
\hline $\begin{array}{l}\text { Providing emotional and psychological support to patients } \\
\text { before surgery from other patients }\end{array}$ & $20(56)$ & $11(41)$ & $31(49)$ & & & \\
\hline $\begin{array}{l}\text { Providing emotional and psychological support to patients } \\
\text { before surgery from professional counsellors }\end{array}$ & $18(50)$ & $8(30)$ & $26(41)$ & & & \\
\hline $\begin{array}{l}\text { Improving knee implants that allow for kneeling, squatting } \\
\text { and walking downhill }\end{array}$ & $31(86)$ & $17(63)$ & $48(76)$ & $29(91)$ & $16(64)$ & $45(79)$ \\
\hline $\begin{array}{l}\text { Improving surgical practices for best healing and scar } \\
\text { minimization }\end{array}$ & $25(70)$ & $11(41)$ & $36(57)$ & & & \\
\hline $\begin{array}{l}\text { Understanding the role of genetics in surgical scar } \\
\text { formations }\end{array}$ & $20(56)$ & $5(18)$ & $25(40)$ & & & \\
\hline $\begin{array}{l}\text { Managing other illnesses while in hospital including } \\
\text { medication interaction }\end{array}$ & $25(70)$ & $15(56)$ & $40(64)$ & & & \\
\hline $\begin{array}{l}\text { Promoting respectful behaviour between patients and } \\
\text { clinicians in clinical settings }\end{array}$ & $21(58)$ & $15(56)$ & $36(57)$ & & & \\
\hline Improving practices for physiotherapy after surgery & $32(89)$ & $23(85)$ & $55(87)$ & $30(94)$ & $23(92)$ & $53(93)$ \\
\hline $\begin{array}{l}\text { Understanding differences between the patient and clinician } \\
\text { views on the right time to discharge from the hospital }\end{array}$ & $24(67)$ & $17(63)$ & $41(65)$ & & & \\
\hline $\begin{array}{l}\text { Effectiveness of discharge to a rehabilitation hospital before } \\
\text { being sent home }\end{array}$ & $25(70)$ & $11(41)$ & $36(57)$ & & & \\
\hline $\begin{array}{l}\text { Integrating family doctors into surgery recovery at the } \\
\text { hospital and after discharge from hospital }\end{array}$ & $23(64)$ & $13(48.1)$ & $36(57)$ & & & \\
\hline Exploring the best role of the surgeon after hospital discharge & $33(92)$ & $9(33)$ & $42(67)$ & $28(88)$ & $9(36)$ & $37(65)$ \\
\hline Effective use of pain medication after hospital discharge & $29(81)$ & $22(81)$ & $51(81)$ & $28(88)$ & $20(80)$ & $48(84)$ \\
\hline Effective support from the health care system after surgery & $32(89)$ & $19(70)$ & $51(81)$ & $28(88)$ & $19(74)$ & $47(82)$ \\
\hline Effective self-management after hospital discharge & $31(86)$ & $23(85)$ & $54(86)$ & $29(91)$ & $23(92)$ & $52(91)$ \\
\hline Promoting exercise following surgery & $33(92)$ & $23(85)$ & $56(89)$ & $30(94)$ & $24(96)$ & $54(95)$ \\
\hline $\begin{array}{l}\text { Providing effective support to patients with ongoing recovery } \\
\text { problems }\end{array}$ & $27(75)$ & $16(59)$ & $43(68)$ & $29(91)$ & $15(60)$ & $44(77)$ \\
\hline
\end{tabular}


The highest levels of support among clinicians were for promoting exercise following surgery and lifestyle changes before surgery to improve recovery (24 clinicans, 96\%). One of the highest ranking topics for patients and caregivers, improving knee implants, was supported by 16 clinicians (64\%).

\section{Interpretation}

This research is, to the best of our knowledge, the first Canadian study to explore TKA research priorities for patients of South Asian origin and demonstrates that research engagement, using a Delphi technique, is feasible in this population. Patients and caregivers declared strong support for all 15 research topics in the second-round survey. This finding was consistent with our design, in which the topics to be included in the surveys were identified by focus groups that included only patients and caregivers. This design reflected our desire to give preeminence to the voices of patients and carers in the foundational work. Clinician support tended to be strongest for topics emphasizing patient lifestyle and recovery. The topic that featured as a top priority for both stakeholder groups was promoting exercise following surgery.

The James Lind Alliance (JLA) recently undertook a research priority setting exercise on hip and knee replacement for osteoarthritis in the United Kingdom. ${ }^{27}$ Their findings relate to a general clinical population; they did not analyze their results by ethnic group or by joint replaced. Some of the JLA-identified priorities (e.g., "What is the most effective pre- and postoperative patient education support and advice for improving outcomes and satisfaction for people with osteoarthritis following hip/knee replacement?") link to those priorities identified in our work but they tend to be broader. The JLA topics make no mention of exercise or lifestyle and no reference to improving knee implants.

In a very different context (developing a child health research agenda), Manikam and colleagues reported a research prioritization exercise also involving families of South Asian origin and health care professionals. ${ }^{28}$ In line with our findings, they concluded that research agendas that include the perspectives of patients and families of South Asian origin can be identified.

\section{Limitations}

Consensus was not reached in our modified Delphi process. However, achieving consensus is not always the objective, and we did not have that as a primary objective in our work. In place of consensus, we highlight variation in the research priorities across the stakeholder groups. The limited discrimination by patients and caregivers across topics is a potential concern. We saw the majority of patients and caregivers indicating strong support for all topics. A further weakness is the relatively disappointing response by the patient and caregiver group to the first round of the Delphi survey (61\%). However, challenges exist for recruitment and retention of research participants in any study, and given the context of our work, we think that the recruitment and retention rates were satisfactory.

\section{Patient orientation}

The adoption of a strong patient-oriented approach strengthened this research enormously. The half-day workshop for key team members including patient partners started the project off on the "right footing," building a team culture of respect for all and an appreciation of contributions from all.

Patient partners also played a critical role in the project's success by enhancing the team's research methods. Some of this related to logistics, such as providing advice on patient recruitment strategies. However, their contribution was more than logistical (e.g., they were involved in generating the Delphi survey topics from the focus group themes). Their presence at all team meetings served as a constant reminder of why this project was so important. In summary, a lesson from this study is that, with appropriate time and effort, patient partners of South Asian background can be effectively engaged in patient-oriented research. Our research had partners engaged throughout the project, providing input on research design, supporting subject recruitment and data collection, working on data analysis and interpretation, and contributing to the writing of the manuscript.

\section{Conclusion}

Our overarching finding is that future research should explore how to improve the experience of South Asian patients who undergo knee replacement. Priority should be given to exercise promotion and self-management following surgery and advancing knee implant technology, especially in relation to kneeling and squatting.

More broadly, our work demonstrates that health research agenda-setting exercises can and should include minority groups, including people of South Asian origin. Through the adoption of a strong patient orientation in this study, culturally specific research topics were uncovered. We would, therefore, like to extend this research to explore the research priorities of patients from other ethnic and cultural backgrounds who undergo TKA.

\section{References}

1. Hip and knee replacements in Canada, 2016-2017: Canadian Joint Replacement Registry annual report. Ottawa: Canadian Institute for Health Information; 2018. Available: www.cihi.ca/en/hip-and-knee-replacements-in-canada -cjrr-report (accessed 2020 Feb. 27).

2. Bourne RB, Chesworth BM, Davis AM, et al. Patient satisfaction after total knee arthroplasty: Who is satisfied and who is not? Clin Orthop Relat Res 2010;468:57-63.

3. Gandhi R, Davey JR, Mahomed NN. Predicting patient dissatisfaction following joint replacement surgery. 7 Rheumatol 2008;35:2415-8.

4. Barlow T, Clark T, Dunbar M, et al. The effect of expectation on satisfaction in total knee replacements: a systematic review. Springerplus 2016;5:167.

5. Choi Y-J, Ra HJ. Patient satisfaction after total knee arthroplasty. Knee Surg Relat Res 2016;28:1-15.

6. Culliton SE, Bryant DM, Overend TJ, et al. The relationship between expectations and satisfaction in patients undergoing primary total knee arthroplasty. f Arthroplasty 2012;27:490-2.

7. Dunbar MJ, Haddad FS. Patient satisfaction after total knee replacement: new inroads. Bone Foint 7 2014;96-B:1285-6.

8. Gibon E, Goodman MJ, Goodman SB. Patient satisfaction after total knee arthroplasty: A realistic or imaginary goal? Orthop Clin North Am 2017;48:421-31.

9. Hamilton DF, Lane JV, Gaston P, et al. What determines patient satisfaction with surgery? A prospective cohort study of 4709 patients following total joint replacement. BM7 Open 2013;3;pii: e002525.

10. Jones CA, Beaupre LA, Johnston DW, et al. Total joint arthroplasties: current concepts of patient outcomes after surgery. Rheum Dis Clin North Am 2007;33:71-86. 
11. Lau RL, Gandhi R, Mahomed S, et al. Patient satisfaction after total knee and hip arthroplasty. Clin Geriatr Med 2012;28:349-65.

12. Nam D, Nunley RM, Barrack RL. Patient dissatisfaction following total knee replacement: A growing concern? Bone foint 7 2014;96-B(Suppl A):96-100.

13. Schulze A, Scharf HP. Satisfaction after total knee arthroplasty. Comparison of 1990-1999 with 2000-2012. [article in German]. Orthopade 2013;42: $858-65$.

14. Vissers MM, Bussmann JB, Verhaar JA, et al. Psychological factors affecting the outcome of total hip and knee arthroplasty: a systematic review. Semin Artbritis Rheum 2012;41:576-88.

15. Goldsmith LJ, Suryaprakash N, Randall E, et al. The importance of informational, clinical and personal support in patient experience with total knee replacement: a qualitative investigation. BMC Musculoskelet Disord 2017; $18: 127$.

16. Bryan S, Goldsmith LJ, Davis JC, et al. Revisting patient satisfaction following total knee arthroplasty: a longitudinal observational study. BMC Musculoskelet Disord 2018;19:423.

17. Chui T. Immigration and ethnocultural diversity in Canada: National Housebold Survey, 2011 [Canadian Government EBook collection]. Ottawa: Statistics Canada; 2013. Cat. no. 99-010-X2011001.

18. Gandhi R, Razak F, Davey JR, et al. Ethnicity and patient's perception of risk in joint replacement surgery. 7 Rheumatol 2008;35:1664-7.

19. Gandhi R, Razak F, Mahomed NN. Ethnic differences in the relationship between obesity and joint pain and function in a joint arthroplasty population. 7 Rheumatol $2008 ; 35: 1874-7$.

20. Keeney S, Hasson F, McKenna HP. A critical review of the Delphi technique as a research methodology for nursing. Int 7 Nurs Stud 2001;38:195-200.

21. Powell C. The Delphi technique: myths and realities. 7 Adv Nurs 2003; 41:376-82.

22. Sumsion T. The Delphi technique: an adaptive research tool. Br 7 Occup Ther 1998;61:153-6.

23. Patton MQ. Qualitative research of evaluation methods. Newbury Park (CA): Sage Publications; 2001.

24. Krueger RA, Casey MA. Focus groups a practical guide for applied research. Thousand Oaks (CA): Sage Publications; 2015.

25. Lincoln YS, Guba EG. Naturalistic inquiry. Newbury Park (CA): Sage Publications; 1985.

26. Mays N, Pope C. Rigour and qualitative research. BMF 1995;311:109-12.

27. Early hip and knee osteoarthritis priority setting partnership. Southampton (UK): The James Lind Alliance; 2016. Available: www.jla.nihr.ac.uk/ priority-setting-partnerships/early-hip-and-knee-osteoarthritis/ (accessed 2020 Feb. 27).
28. Manikam L, Shah $\mathrm{R}$, Reed $\mathrm{K}$, et al. Using a co-production prioritization exercise involving South Asian children, young people and their families to identify health priorities requiring further research and public awareness. Health Expect 2017;20:852-61.

Affiliations: School of Population and Public Health (Bryan), University of British Columbia, Vancouver, BC; Faculty of Health Sciences (Goldsmith), Simon Fraser University, Burnaby, BC; GoldQual Consulting (Goldsmith), Toronto, Ont.; Centre for Clinical Epidemiology \& Evaluation (Bryan, Suryaprakash, Doyle-Waters), Vancouver Coastal Health Research Institute, Vancouver, BC; Department of Nursing (Sawatzky), Trinity Western University, Langley, BC; patient partners (Mulldoon, Le Mercier, Moorthy), BC; Department of Surgery (Gandhi), University of Toronto, Toronto, Ont.; South Asian Studies Institute (Bains), University of the Fraser Valley, Abbotsford, BC; Department of Physical Therapy (Li), University of British Columbia, Vancouver, BC; Arthritis Research Canada (Li), Richmond, BC; Fraser Health (Brown), Surrey, BC

Contributors: Stirling Bryan conceptualized the study and led the design, conduct and analysis of this study and the drafting of the article. Nitya Suryaprakash participated in the design, coordination, data collection, conduct and analysis of the study and helped draft the manuscript. All other authors participated in the design, conduct and analysis of the study and helped draft the manuscript. All authors approved the final version to be published and agreed to be accountable for all aspects of the work.

Acknowledgements: The authors thank the patients who underwent knee replacement, caregivers and clinicians who participated in this research study. They also thank Kusum Soni for her assistance with data collection. They acknowledge the support from study team members Arun Garg, Kristine Juck, Iraj Pourlesami and Rableen Nagra from the BC SUPPORT Unit Fraser Centre. They are also grateful to Fraser Valley Regional Library's Clearbrook Library in Abbotsford, Lakshmi Narayan Temple in Surrey, and the Sunset Community Centre in Vancouver for providing them space, free of charge, to conduct the focus groups.

Supplemental information: For reviewer comments and the original submission of this manuscript, please see www.cmajopen.ca/content/8/1/ E226/suppl/DC1. 